\title{
Interfluxos 2019 | Escola Devir Floresta Conversações: Tania Alice e Luiz Guilherme Vergara
}

\author{
Interflows 2019 | Devir Floresta School Conversations: \\ Tania Alice and Luiz Guilherme Vergara
}

\section{Interflows 2019 | Conversaciones de la escuela Devir Floresta: Tania Alice y Luiz Guilherme Vergara}

Tania Alice *

Universidade Federal do Estado do Rio de Janeiro, Brasil

Luiz Guilherme Vergara Universidade Federal Fluminense, Brasil

https://doi.org/10.22409/poiesis.v20i34.38551

RESUMO: Esta entrevista com Tania Alice, artista-pesquisadora, aborda a trajetória de sua virada do teatro para a performance de arte relacional como cura que hoje vem assumindo uma radicalidade maior como atravessamentos entre projeto artístico, social, urbano e terapêutico. Seus trabalhos também envolvem intervenções urbanas e atravessamentos poéticos coletivos, interlocuções afetivas e sociais entre vidas na escala público e privado. A conversa foi realizada no dia 8/4/2019 no NEPAA, UNIRIO, Rio de Janeiro.

PALAVRAS-CHAVE: performance; arte relacional; cura; atravessamentos

* Tania Alice é performer e trabalha com projetos de performance que se constituem como uma interseção entre projeto social, terapêutico e budista. É professora da Universidade Federal do Estado do Rio de Janeiro (UNIRIO).E-mail: taniaalice@hotmail.com.

Orcid: https://orcid.org/0000-0002-0213-0760 
ABSTRACT: This interview with Tania Alice, artist-researcher, focuses on the trajectory of her turn from theater to relational art performance as healing that today has taken on a greater radicality as intersections between artistic, social, urban and therapeutic project. His works also involve urban interventions and collective poetic crossings, affective and social interlocutions between lives on the public and private scales. The conversation was held on 4/8/2019 at NEPAA, UNIRIO, Rio de Janeiro.

KEYWORDS: performance; relational art; cure; crossings

RESUMEN: Esta entrevista con Tania Alice, artista-investigadora, se enfoca en la trayectoria de su paso del teatro al performance del arte relacional como la curación que hoy ha adquirido una mayor radicalidad como intersecciones entre proyectos artísticos, sociales, urbanos y terapéuticos. Sus obras también involucran intervenciones urbanas y cruces poéticos colectivos, interlocuciones afectivas y sociales entre vidas en las escalas pública y privada. La conversación se llevó a cabo el 8/4/2019 en NEPAA, UNIRIO, Río de Janeiro.

PALABRAS CLAVE: performance; arte relacional; cura; cruces

Citação recomendada:

ALICE, Tania; VERGARA, Luiz Guilherme. Interfluxos 2019 | Escola Devir Floresta Conversações: Tania Alice e Luiz Guilherme Vergara). Poiésis, Niterói, v. 20, n. 34, p. 133-158, jul./dez. 2019. [https://doi.org/10.22409/poiesis.v20i34.38551] 


\section{Interfluxos 2019 | Escola Devir Floresta Conversações: Tania Alice e Luiz Guilherme Vergara}

Luiz Guilherve Vergara: Estamos aqui no dia 08 de abril com Tania Alice, para mais uma conversa e registro de uma experiência que nos interessa para essa rede, ou mosaico de percepções e prospecções, do que seria uma Escola Floresta para a Arte no século XXI ou, ainda, se poderíamos dizer "devir floresta" para a escola de arte. Esse tensionamento da Floresta, da metáfora da Floresta, da realidade da Floresta, como um mundo que não é tão programático, de fissuras nas highways, um mundo multissensorial. Então a gente está conversando e está ouvindo a flauta (que toca em outra sala aqui na UNIRIO). Esse mundo de vários acidentes sensoriais, vários acasos, vários encontros. Então, Tania Alice, gostaria que você pudesse primeiro fazer uma fala introdutória do seu percurso de inflexões. Quando você reconhece a sua primeira, a segunda etc. inflexões conceituais para a performance radicalmente relacional no sentido da revolução de afetos... O que seria esse caminhar dentro da Floresta?

Tania Alice: Nossa! (risos) Boa pergunta! O caminhar dentro da Floresta... Eu acho esse tema muito, muito instigante. Onde flores- 
cemos? Onde nos oxigenamos? Aqui estamos dentro de uma instituição que agora é nossa floresta... Ela tem um tempo outro. Quer dizer, acho que as instituições estão muito atrasadas... Não é o tempo contemplativo da floresta, é um tempo lento mesmo. A floresta precisa avançar, crescer. Porque o mundo está aqui e as instituições estão ali, e nós, artistas, professores, estudantes, no meio tentando entender como juntar essas duas instâncias. Então fico muito feliz mesmo com esse convite de pensarmos juntos, e também de ter a oportunidade de conhecer os pensamentos de outras pessoas sobre esses assuntos. Porque eu acho que a gente está realmente num momento onde as estruturas antigas, do modelo neoliberal, patriarcal, estão caindo aos pedaços; elas não estão acompanhando o movimento do mundo, as urgências do mundo que têm um ritmo outro, não é? E é uma pergunta que está muito forte para mim atualmente, uma pergunta que eu me faço a cada dia que é "onde estar como artista? Como vincular o dentro da academia com o fora?" Realmente é a pergunta que estou, nesse momento, me fazendo com muita força, digamos assim... Às vezes eu sofro de um sentimento de compressão. Estou sentindo uma compressão muito forte, institucional da época atual, que dá pouca liberdade para a gente de fato experimentar, sentir, vivenciar tudo isso que é importante na performance e nos projetos participativos, que é de trabalhar com Tempo, por exemplo. O nosso tempo está sempre comprimido, estamos sempre trabalhando sem tempo, sempre correndo, sempre atrasados, sempre com mensagens urgentes a responder... Eu acho isso um pouco contraditório... Corremos para dentro da sala de aula para fazer meditação, e aí meditamos e tal, e saímos dali e corremos de novo, pegamos o celular e surgem novas urgências... Fica difícil a meditação infiltrar o nosso cotidiano de fato, além da prática formal em sala. Eu acho que está tudo meio contraditório, sabe? A correria não está acompanhando a real demanda das almas. Um dia trabalhei com pessoas do Hospital Psiquiátrico do Rio e a meta era os pacientes criarem uma terapia ideal que os médicos iriam em seguida fazer. E um deles disse: o problema do mundo é que a cabeça anda mais rápido que o corpo e precisamos sincronizar os dois. Aí ele montou um aparelho com computadores antigos, um sincronizador, no qual os médicos dessem forma, porque as coisas não fazem mais sentido do jeito que estão no mundo que a

Tania Alice; Luiz Guilherme Vergara, Interfluxos 2019 | Escola Devir Floresta Conversações. 
gente está. Só que a instituição está ainda formando para o mundo antigo, não se abriu ainda para um mundo novo. Não sei se respondi à pergunta do caminhar, mas são meus questionamentos atuais, que me faço todo dia. "Ainda faz sentido isso que estamos fazendo aqui? Como podemos mudar esse movimento?" Às vezes, tenho a impressão que vamos mudar somente uma coisinha muito pequena, enquanto o que a gente precisava mudar é... sabe... tudo. Reinventar tudo. Estamos dando conta das ondas que vêm, mas esquecemos do horizonte, que é o que faz as ondas virem, o que faz a gente olhar de cima, de longe. Não temos tempo para isso, não tem tempo de compartilhar isso com as pessoas, então ficamos na reatividade o tempo todo. Eu não acho isso saudável. A performance é uma prática de saúde, pode nos lembrar do tempo, do corpo, da potência dos afetos.

Luiz Guilherve Vergara: É interessante que você já tocou na questão do Tempo. As ondas chegam. A compressão das instituições. Mas se nós sentimos a compressão, significa que há um crescimento. Porque a compressão é um sentir de que está em expansão algo que essas paredes institucionais, essas conformações institucionais não estão podendo conter. Então sentir a compressão já é um ponto. Agora voltando, dando chão às suas inflexões, você poderia apresentar esses momentos de suas inflexões entre o instituído e a transformação em sua própria trajetória, em seus campos?

Tania Alice: Pode ser interessante partirmos de uma inflexão bem concreta. Basicamente, estou vendo a arte sempre mais como uma prática de saúde. Pela transformação energética, o trabalho criativo sobre o que nos acontece, podemos promover a cura. Ano passado, com a questão das eleições, pesquisas foram feitas estimando em mais de $60 \%$ dos estudantes, dos pósgraduandos e professores que estão com a saúde mental comprometida, ou tomando remédio, ou com depressão, ansiedade, insônia, questões sérias. Aqui, na Escola de Artes, aconteceram tentativas de suicídio. Ao mesmo tempo, o psicólogo da universidade está com uma lista de espera de mais de cem pessoas em situação emergente e que precisam ser atendidas, e a universidade só tinha, na época, uma psicóloga, que agora são duas.

Você se pergunta se dá para você continuar passando os conteúdos de uma forma nor- 
mal e o que se pode fazer diante de tamanha urgência. A arte é uma questão de saúde. Então resolvi, em fevereiro de 2019, junto com um grupo de alunos de graduação, mestrado e doutorado, montar um experimento que é uma Clínica SomáticoPerformativa. A clínica acontece todas as segundas-feiras, de $18 \mathrm{~h} 30$ até $21 \mathrm{~h} 30$. É um espaço aberto para os alunos, funcionários e professores da UNIRIO; a proposta é desenvolver potências de vida e alegria diante da gente pela prática performativa. São 3 horas toda semana, as pessoas podem ir, podem não ir, podem ir uma vez ou todas as vezes que a pessoa necessitar de um ambiente seguro de criação, baseado numa experiência mais somática. Trabalhamos com meditação budista, temos um cachorro, um golden retriever, um cão terapeuta que está com a gente toda semana. Somos uma equipe com um massoterapeuta, eu mesma sou terapeuta de Somatic Experiencing, a cura do trauma e de Access Bar e Yoga do Riso, temos um artista terapeuta de esquizo-análise, artistas que ministram Reiki. A equipe é composta de diversos artistas e terapeutas, vamos criando junto com as pessoas algo que não sabemos ainda o que é, mas cada semana emerge algo... Algo diferente.
Hoje, por exemplo, vamos trabalhar sobre a questão da autoimagem a partir de um trabalho de Fotoperformance proposta pelo Marcelo, que faz doutorado sobre performance para, com e sobre terceira idade. Nas duas últimas clínicas, trabalhamos com dispositivos performáticos de escuta empática. Na equipe, cada um inventou um dispositivo de escuta empática e levou uma ou duas pessoas para serem escutadas em situações performáticas... Em cima de árvores etc., com conchas e estetoscópios para ouvir a si mesmo, para você ouvir seu coração... Cada um criou um dispositivo. Na clínica, juntamos práticas somáticas e de criação artística. Por exemplo, trabalhamos sobre a questão da insônia, então trabaIhamos com técnicas de relaxamento e criamos juntos um ASMR. A cada sessão, inventamos práticas, não temos um plano, senão que sejam práticas somáticas e artísticas que fortaleçam a conexão e a saúde: temos muitas ferramentas, trabalhamos com comunicação não-violenta, práticas somáticas e aí talvez conecte com as minhas inflexões, porque todos os últimos trabalhos que eu tenho feito eu não tenho trabalhado tanto com planejamento prévio e mais com escuta. Acho que isso é uma inflexão importante. Escutar a demanda, o

Tania Alice; Luiz Guilherme Vergara, Interfluxos 2019 | Escola Devir Floresta Conversações. 
local, o espaço, as pessoas e, com base no que sinto das pessoas, vou trabalhando e criando junto com elas a partir de suas necessidades. Esse é o trabalho da plataforma Performers sem Fronteiras, que atua em zonas de trauma e conflito com projetos artísticos; uma plataforma que criei três anos atrás e que reúne diversos artistas que trabalham em zonas de conflito e trauma.

Por exemplo, essa caixinha aqui é o resultado de um projeto realizado em um prédio da periferia de Marselha, no qual moram pessoas que estão vindo de diversos lugares do mundo em crise, em guerra, que acabam indo para lá porque a moradia é mais barata. Às vezes ocupam, às vezes alugam. São pessoas que no meu primeiro projeto de dança a domicílio eu via muitos dizendo "Ai, eu não tenho motivo para rir". Como essa frase ficava voltando, eu pensei "Vamos rir sem motivo então". Então, comecei a ir de apartamento em apartamento falando "Oi, eu sou Tania Alice e eu vim aqui propor de a gente rir sem motivo, porque não tem motivo para rir, mas eu gostaria de gravar sua gargalhada. Isso é possível?" Aí eles falavam "Tá, vamos lá.". Então, criei um "jogo do riso", onde você sorteia um riso, você chama os filhos, os vizi- nhos, todo mundo... E a gente aplica, tiramos a carta, todo mundo ri junto, então acaba todo mundo rindo. E é aquilo, inicialmente você se força a rir "hãhãhã", mas aí acaba ficando engraçado, aí todo mundo acaba rindo, rindo de verdade. Eu queria e criei um arquivo sonoro com todos os risos do prédio. Assim, as pessoas podem fazer o download e ouvir os vizinhos rindo. E um projeto que eu imaginei a partir das pessoas e do que elas estavam vivendo. Eu já tinha trabalhado lá com um projeto de Dança em Domicílio, que era "eu vou para a sua casa e danço com você a sua dança preferida quando você acordar". As pessoas escoIhiam a música que elas queriam, eu falava, não precisa saber dançar, eu também não sei dançar, é só para a gente mover o corpo. O corpo sabe o que quer, o que precisa, como se cura. Aí trabalhamos toda a parte somática também, que não é do dançar bem, mas que é mais da escuta do corpo. $\mathrm{O}$ projeto incluía uma festa no último dia das três semanas, uma festa em que todos os moradores do prédio se encontravam embaixo do prédio para dançar as músicas preferidas de todo mundo. A ideia era conectar. Eu acredito que a conexão entre as pessoas tem um imenso potencial de cura. Porque eu trabalho a performance de arte 
relacional como cura. A arte tem essa possibilidade de transformação e de cura do outro e da gente. Não é uma coisa messiânica, ninguém está curando ninguém, estamos nos curando juntos, oferecendo possibilidades de campos de cura para o outro se curar junto com a gente. Acredito que a arte tem esse poder. Talvez essa inflexão da arte para a cura tenha sido o cerne da minha pesquisa dos últimos anos. Expandir, enraizar e voar.

Luiz Guilherve Vergara: É interessante voltar a pensar a Floresta, porque quando você fala assim, que você trabalha sem plano, mas há um fio que você traz para dentro da própria sociedade, performance de arte relacional como cura. Essa terapêutica é como se fizesse transfusão de sangue do próprio corpo. Então você pega esse seu agenciamento e devolve. Seja lá em Marselha, um prédio... Que bonita a imagem de você ter um arquivo de risos! Porque na verdade, os vizinhos não se conhecem, ou na verdade, os vizinhos só se conhecem a partir da voz alta quando estão brigando um com outro. Você reconhece a presença do vizinho pela presença de brigas. Então quando você pega isso e devolve... Eu me lembro de acompanhar a sua trajetória com a Yoga do
Riso... E a outra coisa é esse momento em que você está tratando a própria universidade... Então a arte é como se fosse terapêutica da própria arte. Então, seria a Cura pela Arte e seria a Cura da Arte. Seria resgatar uma vitalidade, a necessidade vital da arte por aí.

Tania Alice: A arte institucional do jeito que está, está ficando difícil. Mesmo a performance, nesse novo governo que atua de forma disciplinar, entrou em um esquema que não está me interessando muito. A performance está cerceada. As coisas estão engessadas, institucionalizadas, presas às diretivas absurdas desse desgoverno. Uns anos atrás, a gente fazia teatro, e era a galera de teatro que ia ver outras pessoas de teatro e meio que ficava por aí. Vivíamos na nossa bolha, nosso mundo... Em sua origem, a performance era um transbordamento. Os artistas saiam das galerias, dos teatros, iam para a rua, para entrar em contato com outras pessoas. Só que agora também virou uma coisa que é meio que difícil e cerceada... O mundo está cerceado pelos interesses do capital, que está criando e alimentando afetos tristes. Por isso, é mais do que necessário alimentar os afetos alegres, oferecer espaços de respiro, de alegria... Florestas.

Tania Alice; Luiz Guilherme Vergara, Interfluxos 2019 | Escola Devir Floresta Conversações. 


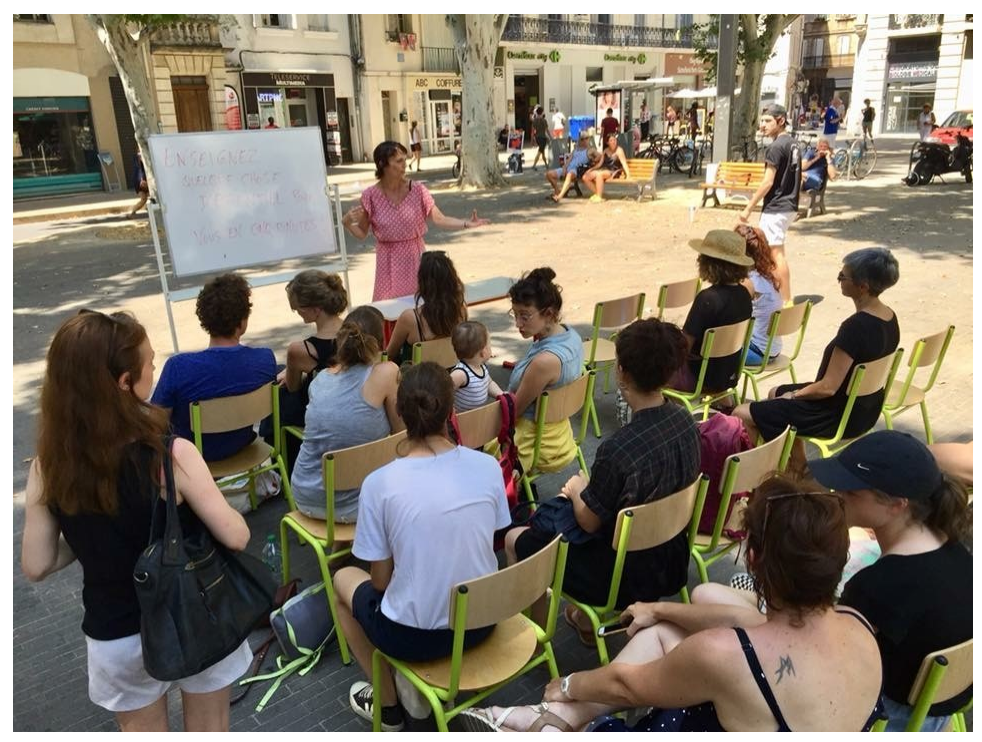

Fig. 1 - Tania Alice, Ensine algo essencial para você em 5 minutos, 2018.

Festival de Avignon, França

(Fonte: Arquivo pessoal de Tania Alice Feix) 
Luiz Guilherme Vergara: É como se a própria instituição fosse gaiola da arte. Está tão previsível...

Tania Alice: É, virou um pouco isso. Jodorowsky dizia "passarinhos criados em gaiolas acham que voar é uma doença". Estamos cercados de pessoas que acham que voar é uma doença. E aí? Se a tua prática artística é ensinar a voar e a voar junto? As pessoas reagem com violência: "Não! Não, não!" Reprimem a energia criativa feminina, reprimem sexualidades não normativas, discriminam, cerceiam a liberdade, porque elas mesmas não vivenciam seus espaços de liberdade. É possível, eu acho que é possível ser livre dentro da instituição, criando uma rede de resistência e de apoio. E em relação ao mundo, temos que estar saindo, voltando para esse outro mundo, com interesses tão distintos do nosso... Mas eu acho que realmente precisamos de uma Outra Escola... Um lugar mais integrativo... Que integre práticas de saúde, prática social e prática artística.

Luiz Guilherme Vergara: E dentro desse seu próprio trânsito, como você chega a arte relacional? Por que a arte relacional, conceituada por Nicolas Bourriaud, aborda um universo de práticas artísticas que já estavam presentes antes mesmo do final dos anos 90 . Como se dá a sua inflexão para a performance relacional? Como uma apropriação que vai além, porque o que você faz de estética relacional pode ser reconhecido como ética relacional.

Tania Alice: É... Começamos lá atrás com os Heróis, não é? Os Heróis do Cotidiano era um coletivo de alunos e professores que se vestiam de super-heróis e iam para a rua fazer ações. Ficamos uns anos trabaIhando nisso e as pessoas falavam muito para a gente: "Isso não é arte!". Na época, o livro do Bourriaud não existia ainda. E eu nunca me importei. Nunca achei que fosse melhor fazer "arte" do que qualquer prática de expressão que faça sentido. A pessoa fala assim "isso não é arte." Eu falo: "Tá bom! Não é arte, então é outra coisa, venha experimentar aquilo que você acha que é." Eu não vejo isso como um problema, definir o que é arte e o que não é. É um discurso que, paradoxalmente, em 1999 estava participando de um debate na França. Em 1999! A questão era "o que é arte? o que não é arte?". Que questão! Se é arte, se não é arte! Já passou esse questionamento, não? Quem diz se é arte? Começa-

Tania Alice; Luiz Guilherme Vergara, Interfluxos 2019 | Escola Devir Floresta Conversações. 
mos com os Heróis do Cotidiano e depois fomos evoluindo para essa estrutura que eu idealizei há uns três anos atrás que são os Performers Sem Fronteiras. São pessoas que fazem trabalhos de arte relacional em zonas de trauma, de crise, de conflito. Minha pesquisa na universidade tem sido "como atuar em Zonas de Trauma", tipo terremoto, atentado, essas coisas e Zonas de trauma continuado - abusos, esquecimento, invisibilidade, pessoas em situação de vulnerabilidade.... E aí desenvolvi não metodologias, mas experiências, dicas para quem quer fazer isso, e um acompanhamento. Não é um grupo, é uma plataforma. Então quem estiver interessado vem e acompanhamos os projetos, aconselhamos, estamos juntos. A pessoa interessada realiza dois projetos com nosso acompanhamento e depois ela pode se tornar um Performer Sem Fronteiras. Trabalhamos também em zonas de trauma continuado. Realizamos projetos junto aos Cuidados Paliativos, em hospitais psiquiátricos, no Retiro dos Artistas, em comunidades isoladas da Amazônia, em locais de Periferias das Periferias das Periferias, eu não gosto dessa palavra, mas só para dizer que é longe de possibilidades de acesso a determinadas coisas que são organizadas de forma cen- tralizada pelo capital. E aí, como atuar nessa existência, no meu trabalho, nesses últimos três anos? Como formar alguém que atue com arte nesses contextos? Porque temos os Médicos Sem Fronteiras, os Enfermeiros Sem Fronteiras, Fotógrafos e PaIhaços Sem Fronteiras, mas não existiam os Performers Sem Fronteiras. O trabalho consiste em realizar projetos participativos, de pessoas que se juntam, que colocam energia em outra direção do que daquela gerada pelo vórtex do trauma. Criamos uma conexão com o grupo, um campo seguro. Escutamos os desejos. Transformamos aquela realidade, a arte é transformação. Quando você começa a estagnar numa coisa igual, não dá. Perdeu a alma, sabe? E precisamos de alma, de poesia, de cura, mais ainda nesses tempos atuais.

Luiz Guilherme Vergara: Essa transformação é até mais forte ainda. Que bom que você se inspirou nos Médicos Sem Fronteiras. Um dos alunos do mestrado, ele não é do mestrado, mas está assistindo aula, ele é do mestrado de Saúde Coletiva. E a Saúde Coletiva é um programa também com muitas influências espinozianas do afeto, e de uma atuação de acompanhamento coletivo. Mas o fato de ir para essas realidades se apro- 
xima da formação artística... como se fosse terapeuta social, ou voltado para terapêuticas antropofágicas. Vai apontar para as fronteiras de ação dentro das fissuras onde há o abandono (social-cultural). Acrescenta-se ainda uma prática em jogo no programa espinoziano de Saúde Coletiva que é o pensar escutar, como um médico vai escutar o paciente, tem-se a escuta social de múltiplas vozes. Eu acho muito bonita essa imagem de convergência entre terapêuticas sociais e práticas artísticas relacionais. Como é que se forma esse artista conector? Escutador? Isso seria um encaminhamento propositivo para pensar uma Escola Floresta com esses atributos. Qual seria a equivalência daquela maleta de médico para esse artista da performance relacional? Como vai ser essa maleta desse artista? O que ela levaria?

Tania Alice: Exatamente. É isso que eu estou querendo investigar agora. Eu quero ouvir isso do mundo, sabe? Como é que é isso? O que as pessoas que estão lá no fundo da Floresta estão pensando sobre arte? O que que eles propõem como práticas possíveis para um artista? Quero ouvir essas pessoas e ver como a gente cria com os ensinamentos dessas pessoas. Eu acho que é uma outra coisa para se pensar. Que do jeito que está, não dá mais. Ou ainda temos 20, 30 ou 40 anos mais (?). Estamos destruindo o planeta. Meu último projeto chamava "Ensine-me a fazer arte". Eu viajei através de quatro continentes para ouvir as pessoas respondendo à pergunta "O que um artista deve fazer hoje?" Convidava-as para vir assistir à realização das respostas no dia seguinte. Depois, desenvolvi um solo que junta a execução de todas as respostas que realizo, respostas da África, Europa, América Latina e Índia. O solo também fala da situação política atual. E aí, o que acontece? Apresento fora, mas aqui no Brasil, só consegui fazer uma apresentação até agora.

Luiz Guilherme Vergara: O próprio sistema está doente. A arte tem que fazer quase que uma auto-terapia ocupacional incluindo o próprio sistema de formação de artistas, assim também o sistema de circulação pública da arte, seu circuito de consumo e prática social de recepção. Todo esse circuito está doente. Então como criar linhas de fuga? Linhas de oxigenação? Linhas (orgânicas) de Florestas. Acho que isso é importante e urgente. Fala um pouco da Yoga. Essa Yoga do Riso que você faz. Comenta isso. Como isso está afetando a sua própria prática? 

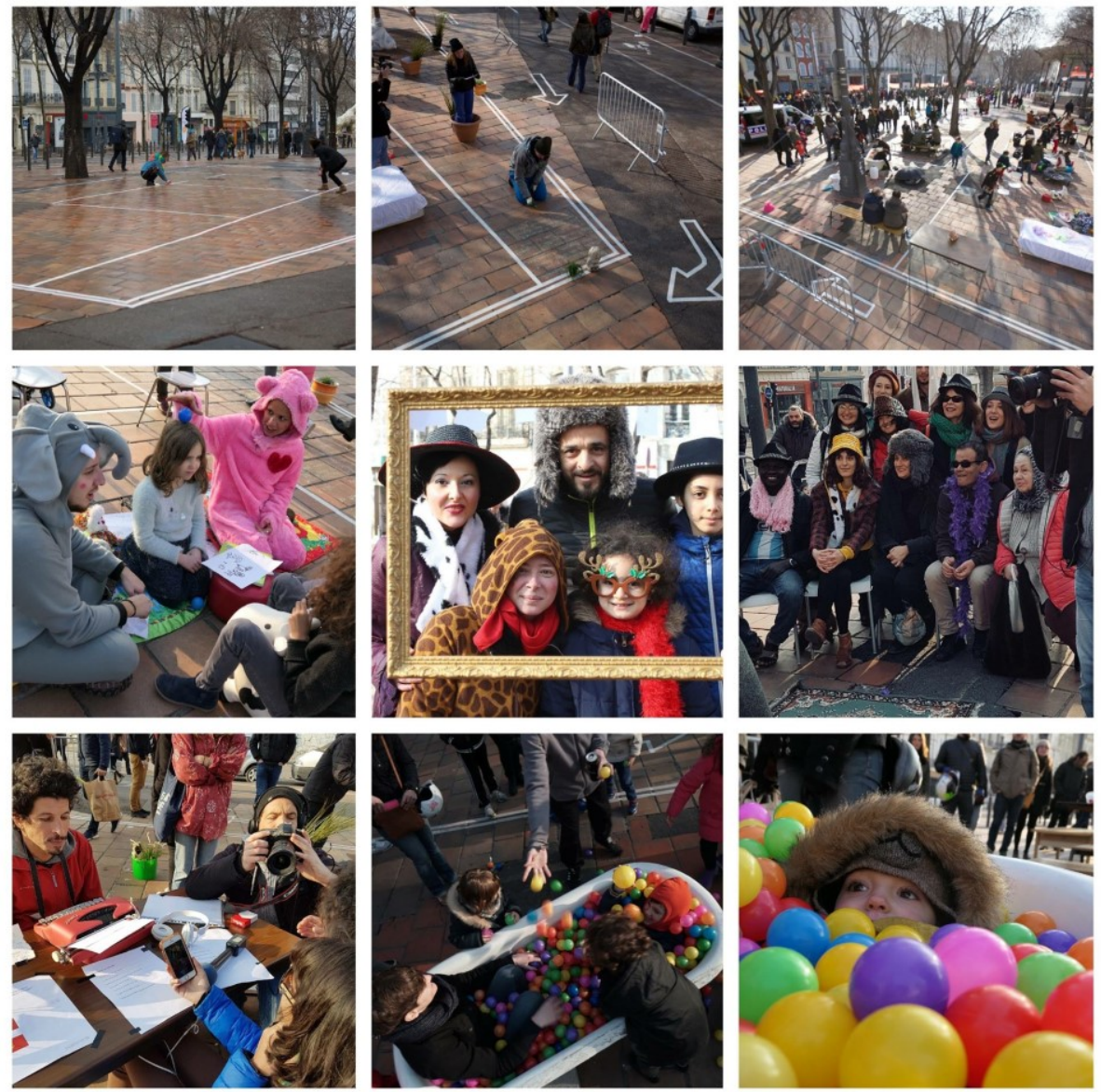

Fig. 2 - Tania Alice, Dans ma maison, 2018.

Marseille, França

(Fonte: Arquivo pessoal de Tania Alice Feix) 
Tania Alice: Retomando um pouco o percurso... Porque essa junção das práticas e experiências somáticas, a Yoga do Riso, essas práticas que estão junto com a prática artística que eu faço, ela aconteceu graças a um pessoal dos Estados Unidos, com quem eu trabalhei no CalArts (Califórnia Institute of the Arts) quando obtive a bolsa da Fulbright. Quando trabalhei lá, eu era artista convidada e fazia um projeto na época, em volta da minha cama. Na época, eu levava minha cama para diversos espaços públicos, inclusive levei para o MAC na época das remoções, lembra? E as pessoas vinham para anos. Quando eu estava trabalhando no CaIArts, um dia eu fui propor numa comunidade afro de colocar a cama lá. E o líder falou "maravilha! vem!". E eu não sei o que aconteceu, mas quando eu cheguei para botar a cama, tinha um monte de gente esperando. Muitas pessoas! Muitas mesmo. Aí chegou o primeiro, "ah, porque eu estou tomando drogas" e me contou a vida dele, e aí vem a próxima "ah, eu estou querendo fugir de casa, não aguento mais meus pais" e tal... Comecei a mobilizar os recursos que tinha de escuta empática, Comunicação Não Violenta, essas coisas. Daí o quarto entrou e disse, "Essa coisa de terapia na cama é maravilhosa. Porque se a gente tivesse que ir para o terapeuta, a gente jamais iria. Mas assim, aqui na comunidade, a cama, ao ar livre, a gente fica muito confiante, é muito legal". Ou seja, essa coisa da arte junto com a terapia fazia sentido para as pessoas. Se fosse só uma performance em que eu estivesse na cama contando os meus problemas, não ia ter muito interesse para ninguém. E o fato de eles falarem "é isso", pensei "gente... eu preciso me instrumentalizar nisso". E aí fui fazer uma formação de três anos Experiência Somática, que é a Cura do Trauma, e isso foi muito intenso. Mudou minha prática artística totalmente. 
O Projeto dos Abraços resultou dessa junção. E um projeto em que eu uso a Experiência Somática. Depois eu fui juntando outras coisas, como a Yoga do Riso, que deu esse projeto do riso, o Access Bar que eu fiz agora, que acho muito interessante. Mas a Experiência Somática é uma prática muito potente. O projeto dos abraços foi um projeto que surgiu depois do terremoto no $\mathrm{Ne}$ pal. Como eu tenho a prática budista também, eu fiquei muito mexida com o acontecido, com uma sensação de impotência do tipo, "Caramba, o que a gente pode fazer? Tem um terremoto e a gente como artista aqui continua fazendo teatro como se nada tivesse acontecido? O que podemos fazer de fato?" E pensei, "acho que posso levar afeto, levar abraços". Será invisível e não poderá ser taxado na fronteira. Então, durante três meses eu fiquei coletando abraços longos. Eu tinha um cartaz que dizia assim "Me dê um abraço de 5, 10 ou 15 minutos, e depois eu vou levar para o destinatário". Então, a pessoa me dava um abraço, ficávamos abraçados 5,10 ou 15 minutos, e a pessoa dizia, "eu vi uma senhora de 80 anos" ou "eu vi uma mãe com filho, que perdeu a casa", ou "eu vi um senhor de 80 anos que perdeu a casa e a esposa"... ou escolhia um destinatário: um bebê, um se- nhor... Fiz uma lista destes destinatários, tinha 149 pessoas. E fazia a foto de quem estava mandando o abraço. Cheguei no $\mathrm{Ne}$ pal com essas 149 fotos e destinatários de abraços e fui procurar as pessoas. Quando achava a pessoa, eu dizia "essa pessoa aqui soube que aconteceu um terremoto, que você perdeu a sua casa, e ela está te mandando um abraço de 15 minutos. Você quer?". E aí a pessoa falava "sim", e eu dava o abraço e trabalhava a parte somática. Porque, por exemplo, quando você passa por uma experiência de terremoto, você perde a conexão com chão. Parecia que o corpo das pessoas estava flutuando. Tem uma desconfiança somática com o chão. Se você enraíza com essa questão do espeIhamento, você vai trabalhando a sua conexão e você sente o corpo da pessoa fazendo assim... "uff". Soltando. Experiências, como atentados, terremotos geram estados de imobilidade com medo. É tipo um congelamento. Então você pode oferecer uma prática artística onde você tem um estado de imobilidade sem medo. No abraço, por exemplo, o corpo descongela, aí ele descongelando, ele descarrega o stress. É a partir daí que você pode mudar alguma coisa de fato. Depois do abraço, eu dava a foto da pessoa que tinha enviado o abraço 
para o destinatário e mandava de volta a foto de quem tinha recebido com a mensagem: "olha, seu abraço chegou". Passei dois meses procurando 149 pessoas, e consegui entregar o último no aeroporto, na hora de ir embora. Entreguei todos. Foi uma experiência... Foi outro mundo... $E$, depois, eu fiz esse jogo da memória. Jogando, você associa quem deu o abraço e quem recebeu o abraço. (Porque tem a mesma foto aqui). E você jogando, você lembra que a conexão entre as pessoas que faz você ganhar e superar um sentimento de ansiedade e desconexão. Se você conecconecta pessoas, você não ganha. A ideia é que, jogando, essa ideia fique corporal; eu conecto afetos e, conectando afetos, vou de alguma forma fazer alguma coisa. Esse é o jogo.

Luiz Guilherme Vergara: É a questão da conectividade, não é? O quanto a gente pode explorar a conectividade? Existe essa relação de conectividade na arte como uma potência de transferência. Os africanos têm isso também. Por exemplo, você faz um bonequinho e você transfere para aquele bonequinho a memória de um ente querido que se foi. Você faz um altarzinho... Esse

poder de transferência afetiva, de conectividade, através de objetos ainda é muito pouco aceito entre nós, ocidentais. A sua proposta absorve, passa a ser exatamente a transferência. Então quando você faz isso, você duplica esse contato. Não apenas você ter encontrado, mas você estar transferindo a energia da pessoa para uma outra. Que duplicação! Que possibilidade é essa? lindíssimo! É um resgate de conectividade que remete a outros valores (talvez fundamentais e ancestrais) da arte. A arte concreta, que reivindicava a autonomia e objetividade da forma, também reprimiu outras potências de subjetivação, subjetividade e espiritualidade.

Tania Alice: É porque é visto como cafona, você falar de espiritualidade na academia... é uma questão; você falar de natureza na academia é uma questão. Você falar de floresta na academia é uma questão para alguns. Você falar de sexualidade e nudez na academia é uma questão. São tantas questões... Você falar de bruxas na academia é uma questão... Não vi um mestrado ainda sobre bruxas. Pode ser que tenha. Mas eu ainda não vi. Cadê as bruxinhas? Aquelas que redescobrem sua força e energia criativa abafada pelo sistema patriarcal? 


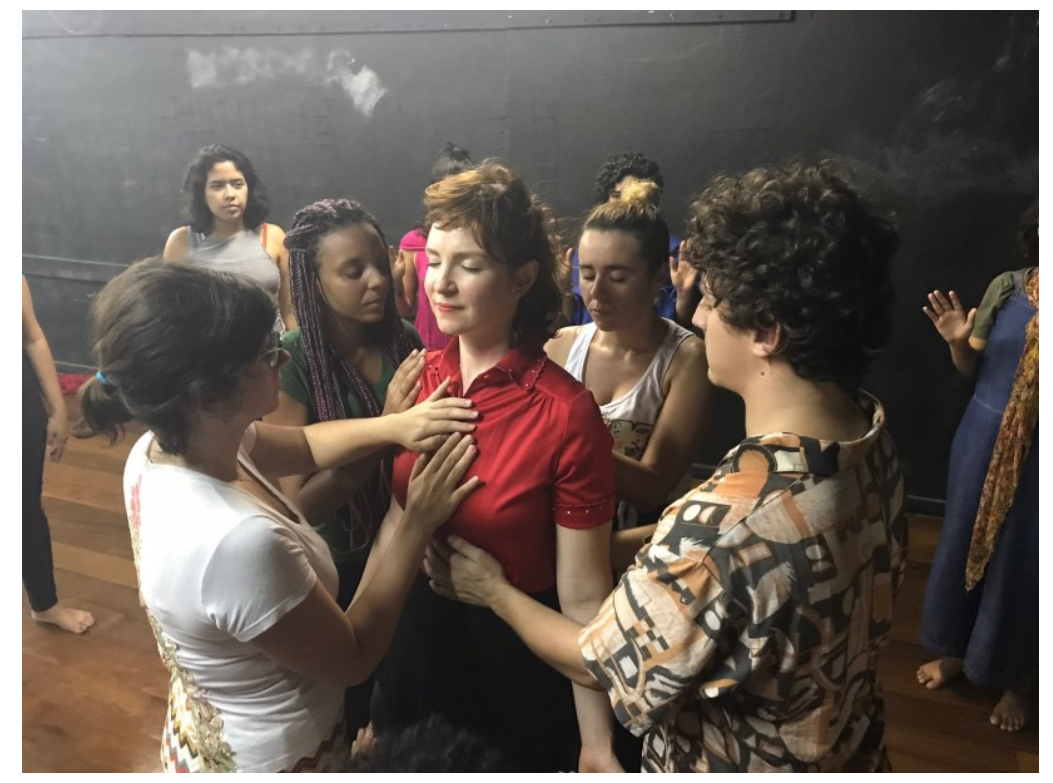

Fig. 3 - Tania Alice, Clínica Somatico-Performativa, 2019.

(Fonte: Arquivo pessoal de Tania Alice Feix) 
Luiz Guilherme Vergara: Sim, até porque já estamos nos aproximando de uma noção, de um entendimento do feminismo, que está avançando de tal forma, que nós todos, inclusive eu, temos que rever nosso conjunto de bibliografia e tudo mais. Porque fomos formados por uma história da arte amparada pela visão europeia e, de repente, todos esses valores estão desmoronando... E cadê o lugar da Floresta?

Tania Alice: Nós aqui conversando isso, e ao mesmo tempo "o outro lá" querendo reescrever os livros de história para dizer que da esquerda. Diante dessa macropolítica estabelecida em cima de fake news, tenho a impressão que a gente está naquela história do colibri, do Pierre Rabhi, que lançou todo o movimento da Sobriedade Feliz. Você ser feliz com pouco, o minimalismo... Ele conseguiu esse entendimento, que na verdade é uma grande sabedoria. E ele criou comunidades na França, que são autossustentáveis, baseadas em ecologia, como aqui tem a Terra Una, por exemplo, também temos esse tipo de comunidade aqui no Brasil. Só que lá é um movimento maior. O movimento chama Colibri, porque é aquela história do passarinho que vai levando as gotinhas

d'água. Perguntaram para o passarinho: "por que você está fazendo isso?" e ele respondeu: "estou fazendo a minha parte". Eu sempre acreditei muito nisso. Só que atualmente eu tenho a impressão que é o incêndio do mundo é maior. Periga engolir o passarinho e todo resto. Ele está lá tentando, tentando, só que a coisa é tão maior, tão articulada com o sistema neoliberal... Eu não sei, essa minha visão mudou com o assassinato da Marielle. Mudou muito minha visão do humano, do mundo, de tudo. E é complexo, não é? E agora o que a gente pode fazer de fato para que se expanda a nossa bolha? Precisamos acessar outros reservatórios de forças para dar conta desse mundo atual.

Luiz Guilherme Vergara: Eu tenho tratado essa questão com o que eu chamo de microgeografia de afetos. Até por ter visto no MAC essa questão de uma expectativa monumental, aquela arquitetura. Mas o que me encantava lá era aquilo que você fez. Era o efêmero. Uma coisa como que um Do In e o próprio MAC fica como um Do In dentro da Baía de Guanabara. Então é um contraponto em relação a isso tudo. A gente está tendo uma macroexperiência, que gera uma endemia do medo. O caso, por

Tania Alice; Luiz Guilherme Vergara, Interfluxos 2019 | Escola Devir Floresta Conversações. 
exemplo, do sacrifício e execução política da Marielle. Ela foi sacrificada. E hoje a todo momento, mais uma rua no mundo é chamada de Marielle. Então há um fenômeno da Marielle, que a gente ainda não se deu conta. Ela foi catapultada para a dimensão da lacuna do simbólico. Esse caso da Nova Zelândia, por exemplo, que teve aquela execução, não sei se você viu isso... A Primeira Ministra abafou para que não tornem, esses loucos que fazem essas execuções, genocídios e tudo mais, que não se tornem heróis. Porque, na verdade, há também uma cultura visual que os trata como heróis. E ela criou uma dobra para a gente não ser multiplicador da negatividade. E para mim, o negar a negatividade, é isso que você faz, é o Colibri mesmo, é o microgesto dos Heróis do Cotidiano. É daquele jovem, Marcelo Asth, fazendo aquela intervenção de performance para idosos. Trazendo alegria. Isso é uma contramão.

Tania Alice: O Marcelo [Asth] está há um tempo desenvolvendo essa pesquisa, que é maravilhosa. Desenvolveu no mestrado, está terminando no doutorado, a Performance Para Com e Sobre as pessoas de mais de 60 anos. Quando Marcelo fez a prova de doutorado, algumas pessoas alegaram que aquilo não era arte. Ele acabou passando, hoje é bolsista nota 10 da Faperj e desenvolve um trabalho muito poderoso. Temos que infiltrar os espaços, criar fendas, dobras pelas quais o oxigênio e o amor possam circular.

Luiz Guilherme Vergara: Você está gerando uma escola. O Marcelo amplia suas influências, porque ele é jovem, faz contato, resgata o espírito de atividade poética para pessoas que não estavam mais contempladas pela atenção ou cuidados da sociedade ou cidadania. Há uma condenação da idade a não ser mais poética - criativa. O estado poético se restringe ao jovem. A vanguarda é jovem. E as pessoas estão cada vez mais envelhecendo mais cedo. Quando chegam aos 30, já não são mais jovens. Tem uma cobrança nessa situação. Então voltando ao colibri, o colibri é um contrafluxo. Agindo de dentro do incêndio na Floresta, como o colibri que não se assusta com o fogo. Ele vai e volta. A gente tem falado muito sobre linhas de fuga, de fazer uma costura mesmo Do In. Como a gente traz isso, para um campo de formação de (novas) escolas de arte? Porque você é um colibri dentro da faculdade (UNIRIO), não é? Mas a arte faz também um papel de colibri dentro das uni- 
versidades. Porque é uma minoria que faz arte; igualmente de uma minoria para uma minoria. Estamos falando realmente de uma minoria em termos de classe social. Qual o montante de gente, de jovens que decidem fazer arte nesse país? Que modelos de devires possíveis temos de fato oferecido para "ser artista no Brasil"? É daí que podemos incluir as terapêuticas sociais da arte sobre a arte. E você está atuando nesse sentido... são pessoas que não têm problema de tratar da solidão, da espiritualidade, do envelhecimento. Se tem um tambor aqui, já se tem uma invocação.

Tania Alice: É eu fico pensando na universidade, como até o vocabulário é cooptado pela dominação... Sempre que uma pessoa fala assim de disciplina e grade, como isso é militar, não é? Outro dia em uma banca de doutorado, o Charles Feitosa, filósofo e professor daqui dizendo que se a gente pegasse uma pessoa da Idade Média e transportasse ela para agora, ela iria estranhar muita coisa, a maneira de vestir, de se comportar, uma série de coisas ela ia achar curiosa, mas tem três coisas que que ela ia achar iguaizinhas: a escola, a prisão e o manicômio. Não mudou em quase nada, mais ainda agora que estamos andando pra trás. Porque são lugares fechados, onde é decidido quem entra e quem sai. Você não pode sair como você quer, você não pode fazer o que você quer. O corpo não é livre, ele é controlado por outros que sabem o que é bom para ele, em função de parâmetros de normalidade por eles estabelecidos. Conseguimos inventar um monte de coisas, conseguimos ir para outros planetas, mas não conseguimos reinventar a escola. A gente não consegue. A gente tenta, mas é difícil. Temos aquelas reuniões que duram seis horas e, no final, mudou... mudou o quê? Ficamos cinco horas e meia reforçando aquele status quo das coisas como elas são, porque "Meu Deus, não dá para mudar aquilo tudo de uma vez". E por que não? E você sai daquilo e mudou um pouquinho só. E o mundo está explodindo. Parece que a universidade não acompanha. Ao mesmo tempo, não tem outro lugar para as pessoas. Eu acho que dentro do mundo, a universidade ainda é um lugar muito incrível, que te dá muitas possibilidades de conexão, de encontro, de criação, de liberdade, de potência, mas há de se resistir. O otimismo, ele é um exercício diário. Ele é a revolução. Não cair nos afetos tristes e manter a amorosidade é uma prática diária. Inclusive, nessa Escola Nova tinha que ter uns Módu-

Tania Alice; Luiz Guilherme Vergara, Interfluxos 2019 | Escola Devir Floresta Conversações. 
los de Otimismo, Meditação Tibetana, Yoga do Riso, Sexualidade Tântrica etc., porque está tão fácil se deixar levar... Eu acho que essa injeção de ânimo é bem importante. A gente tem que conseguir isso todo dia.

Luiz Guilherme Vergara: A separação dos campos tem me provocado muito. A separação dos campos é uma inflexão. O Mário Pedrosa tem um texto de 1960, que ele fala do experimental na arte como instrumento de síntese. Eu acho esse texto ainda pouco revisto e entendido. Esse instrumento de síntese, toda vez que eu falo nisso, na academia, intelectuais da academia veem problema porque síntese, para essas pessoas, seria uma unificação para uma única ideologia. Como abordar o acontecer de síntese não sendo monótono, de apagamento de diferenças. O pensar de síntese é um pensar, acredito, Pensar Floresta, é um pensar de polifonias. É integrativo de singularidades. A arte é um instrumento de síntese... Você descreveu várias situações em que a arte foi ali um instrumento de síntese, porque era algo que unia várias camadas de trauma, de memória, de isolamento, de solidão, de terapêuticas sociais, como arte. Então, essas práticas artísticas eram tomadas como instrumentos provocando um re- conectar de diferenças como síntese. Dentro dessas indagações finais, o que a gente busca também é como fortalecer a relação desse experimental, em cursos de Arte que envolvam performance, vivência, tudo que não é objeto isolado, mas gerador relacional. É como lidar com a criação, a criatividade, a invenção e a reflexibilidade. Para que não fiquem isoladas as "tribos da teoria" e as "tribos do andar de cima", que seria o que olha teleologicamente teorias sobre teorias, e a "turma que está na ação direta ao rés do chão", agindo no território existencial de vivência, dos afetos e da produção de subjetividade. Como aproximar a criação com a reflexão, ou experiência e conceito? Como você ao fazer e ser Escola desse Riso, trazer saberes que são da Yoga, da Experiência Somática, outros saberes que não passam pela história eurocêntrica e colonizadora da arte. E como você produz a confluência entre pensamento-sensibilidade; pensar sensível? Como você está enfrentado esse confronto ou fratura da razão ocidental?

Tania Alice: Na pesquisa artística, que é a pesquisa da nossa vida, as questões aparecem de forma orgânica. Eles estão ali antes e seguem depois, o estudo formal é somen- 
te um parêntese de enquadramento institucional, não é? Isso acontece tanto para a gente quanto para as pessoas que acompanhamos em suas pesquisas de mestrado, doutorado. O problema é que, às vezes no modelo de curso tradicional e nos projetos, os pesquisadores definem previamente uma bibliografia, sempre majoritariamente eurocêntrica e masculina, definem os objetivos a serem atingidos, o caminho por onde tem que ir, a tal da metodologia. Parece que o pesquisador já sabe onde vai e não se dá o tempo de ficar no escuro, na incerteza. Muitas vezes, copiamos um modelo científico para a arte, ao invés de re-inventarmos e cartografarmos nossas práticas. Nas bancas de seleção de projetos de mestrado e doutorado, às vezes as bancas exigem que o projeto de um mestrado de uma pesquisa artística saiba para onde ele vai, que produto vai se criar e, com isso, a essência da pesquisa, que se localiza em um não saber e um questionamento muitas vezes intuitivo, desaparece um pouco. Porque na pesquisa você não sabe. Você pode estar lá durante meses com aquela questão e aquela questão não se resolve. $E$, de repente, alguém vai te falar algo durante uma performance ou em qualquer lugar e aí você para, ouve a tua intuição e corre atrás, lê, viaja, e "nos- sa!", tudo começa a fazer sentido e você começa a ver que caminho você quer seguir. Só que esses tempos são orgânicos, eles não são do chronos racional, digamos, em três meses eu tenho que cumprir isso, em quatro meses eu tenho que cumprir aquilo, em cinco meses eu tenho que ter feito a minha performance pelo menos três vezes para poder ter elementos para qualificar. Parece que é uma coisa meio antinatural, não é? Eu percebo que, em muitas vezes, que esse modelo de escola que temos, colocamos as pessoas como aqueles gansos com os quais as pessoas fazem foie gras; só que são exercícios para se fazer textos para ler... A pessoa que faz faculdade se sente sufocada, estressada. Ela não tem nem mais tempo de saber o que ela realmente quer. $O$ que ela realmente deseja. $O$ que ela tem de curiosidade. Quando você vai fazer um projeto participativo com uma determinada comunidade, você olha para o corpo das pessoas, você observa o momento em que aquele corpo acende e aí você sabe que pode trabalhar esse tema ou essas questões. O corpo tem que poder ter tempo de acender. A partir daí, dessa chama inicial, entra o interesse pela leitura, pelo conhecimento, pela escrita. Essa coisa que a gente mescla, as leituras, com o que a gente ouve, com o

Tania Alice; Luiz Guilherme Vergara, Interfluxos 2019 | Escola Devir Floresta Conversações. 
que a gente sente, com o que a gente percebe, essa percepção sinestésica do mundo, a escrita também ajuda a colocar isso em palavras. Então, eu acho muito bom ter essa prática da escrita também, nas aulas, nos projetos. Mas o ponto inicial tem que ser uma chama, algo que acende o coração. Muitas questões clareiam escrevendo. Essa prática da escrita com desejo, acho que é basicamente isso, é um conhecimento com desejo. É fundamental você querer aprender. $\mathrm{E}$ você tem o direito de não querer também. Um dia eu dei um curso de performance socialmente engajada com o tema "Vamos aprender o que queremos aprender". Fizemos uma lista de coisas como fazer sushis, saber andar de bicicleta, cantar um canto gregoriano em latim e a aula toda consistiu em aprender essas coisas juntos. Nas aulas de performance, eu sempre digo: "se tem alguma coisa que você não quer fazer, não faça. Você não é obrigado a fazer nada. Já basta o mundo obrigar a gente a fazer mil coisas". Eu dou a possibilidade de você fazer aquilo que você deseja fazer. Tem muitas maneiras de estar junto com um grupo, mesmo não realizando a performance. O poder de escolha empodera, mesmo se não gosto muito dessa palavra... Tem momentos que a gente precisa se tran- car, ficar só lendo e pensando. E tem momentos que a gente não quer nem saber. $A$ gente precisa experimentar, e fazer, e fazer de novo, e "não é", e bate cabeça e tal. E em alguma hora, acontece. Esse ritmo é natural. Mas tem uma questão também que nas escolas temos uma cultura do sucesso, que acho péssima para a arte, porque muitas vezes você não ter sucesso é muito mais interessante do que ter sucesso. Às vezes, aquele projeto que não funcionou, que você não conseguiu fazer, você aprendeu tanta coisa com ele... E, às vezes, aquele que deu super certo, vendeu e teve sucesso, você sai igual daquilo. Todo mundo sai igual. Você criou mais um produto que funcionou. $E$ a gente valoriza muito... A pessoa quer ser aprovada na disciplina, mas, às vezes, é melhor não. Às vezes é melhor refazer, é melhor ter um tempo. Mas a gente está muito nisso... Acaba rápido, se forma rápido! Para quê, gente? "Quer sair mesmo daqui? Olha como está lá fora!". Às vezes, é melhor tomar um tempo, curtir, criar e viver plenamente esse oásis aqui.

Luiz Guilherme Vergara: Essa pergunta está acompanhando várias pessoas que lidam com o pensar uma escola de arte, ou universidade de arte, no e com o mundo con- 
temporâneo. Participei com a artista pesquisadora em performance e ação coletiva, Dasha Lavrennikova, em uma vídeoconferência para Moscou através de convite da Professora Yulia Liderman ${ }^{1}$, como parte de uma conferência internacional - Arts Lab in Performative Arts: Between a Metaphor and a Practice, onde se discutia a formação da escola-artista a partir dessa relação de práticas artísticas e práticas sociais. É possível se reconhecer o crescente interesse nessas questões na Europa, abordando as práticas sociais, clínicas, ambientais e cognitivas. Observou-se ainda o interesse da Yulia em desenvolver um estudo integrado, principalmente com o pessoal de performance e teatro. É nessa frente que eu estou encontrando algumas referências muito instigantes. Ontem eu fiquei me deleitando com as inferências de Erin Bunny, Stefan Hawney, Fred Multer, Brian Massumi, todos lidando com corpo, performance... Erin Bunny elabora a "estética do entusiasmo," eu fiquei apaixonado! Estas tendências estão transbordando o campo das artes visuais, tendo a Lygia Clark como uma importante referência. A Lygia Clark deu esse salto. Embora ela não estivesse chamando de estética relacional, a partir da Nostalgia do Corpo, seu trabalho-processo se torna um grito de eclosão da sensibilidade! A linha orgânica já inaugura seu devir de gritos para além da arte concreta. Linha de fuga. A linha como aresta de encontro entre superfícies. Você está vendo aqueles dois tijolos juntos formando uma linha entre eles, mas não é uma linha desenhada. É uma linha de ar. Uma linha orgânica. Esta percepção da Lygia traz, para a produção de sentidos, o vazio, o espaço entre as formas construídas. Este respiro da des-forma antecipa e incorpora os incômodos dos artistas com o formalismo ortodoxo, saindo e encontrando a Floresta, o cosmos, a espiritualidade.

Tania Alice: É isso! Precisamos criar a partir do nosso desejo de criar novos mundos e não gastar energia se revoltando contra o antigo. Porque é isso que o sistema quer. Com os afetos, a gente consegue dar um curto-circuito no sistema. Que a gente consiga criar essa Escola rapidamente!

Luiz Guilherme Vergara: Mas essa Escola não vai ter endereço. Ela já é. A gente já está formando uma conspiração. Porque tem que ser Floresta, porque não pode ter parede. Você já é.

Tania Alice; Luiz Guilherme Vergara, Interfluxos 2019 | Escola Devir Floresta Conversações. 


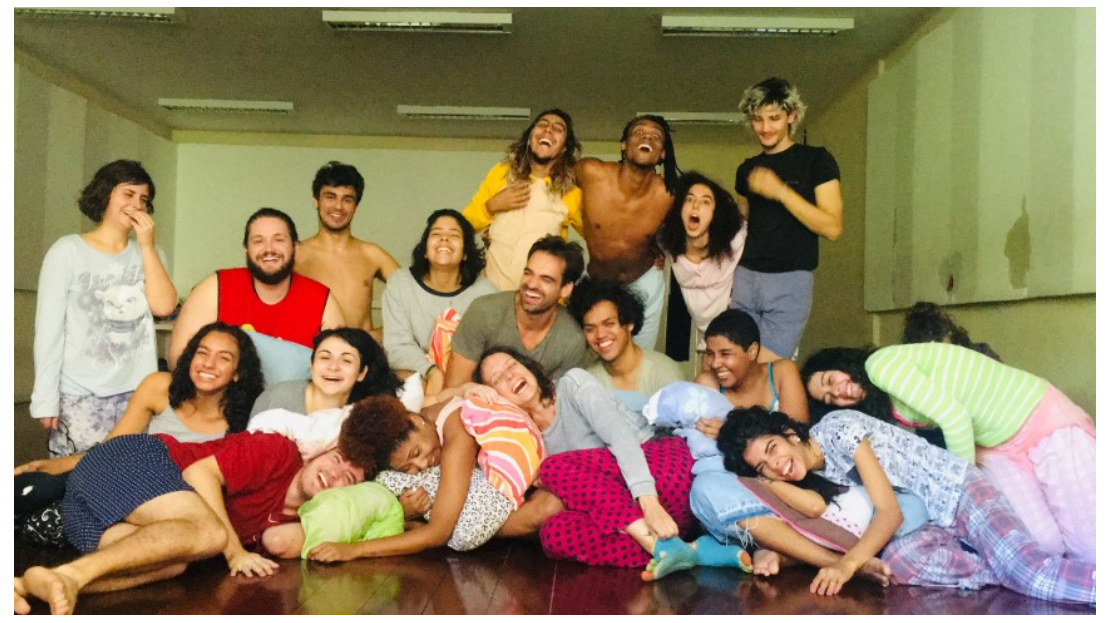

Fig. 4 - Tania Alice, Yoga do Riso, 2019.

(Fonte: Arquivo pessoal de Tania Alice Feix) 
Gabriela Bandeira: Eu fiquei pensando quando você falou dos Performers Sem Fronteiras, sobre essa ação de trauma contínuo. O lugar de onde venho é um lugar de trauma contínuo. Nasci numa aldeia caiçara; eles eram pescadores urbanos e perderam tudo em 2002, por causa da Petrobras que despejou óleo na baía. Então, até hoje eles sofrem com uma memória de uma coisa que eles nunca mais vão ter. E como é importante, às vezes, só ouvir, não planejar nada. Sentar lá e só ouvir o que eles têm para contar. Isso conforta eles de alguma forma, por estar passando uma identidade daquilo que eles viveram para uma pessoa que não conheceu e não viveu. Acho que talvez seja a mesma satisfação de trabalhar com idoso. De você compartilhar uma coisa que, para ele, é tão cara e que você acaba se sentindo pertencente daquilo tudo, não é?

Luiz Guilherme Vergara: A gente está pensando em termos de irradiações para fora das paredes institucionais que a gente possa desenvolver. O trabalho da Gabriela Bandeira fez parte de um projeto de colaboração entre o curso de arte da UFF e o MAC. Não sei se você foi ver a exposição Águas e Vidas Escondidas (2016). Então, ela entrou no mestrado e a gente está que- rendo criar uma rede de atuação no Gradim, bairro de São Gonçalo. Como se fosse um núcleo de ação comunitária.

\section{Notas}

1 Yulia Liderman é professora doutora da RANEPA School for Advanced Studies in the Humanities, The Centre for Studies in History and Culture, Moscou, Rússia, onde pesquisa Arts Lab com foco nos contextos sociais. 